\title{
The Effect of Gertain Steroids Upon the Growth of Trichophyton rubrum
}

\author{
By F. W. CHATTAWAY AND J. D. TOWNSLEY \\ Department of Biochemistry, University of Leeds \\ AND A. J. E. BARLOW \\ Department of Dermatology, The Royal Infirmary, Huddersfield, Yorkshire
}

(Received 30 August 1961)

\section{SUMMARY}

\begin{abstract}
The effect of thirty-seven different steroids on the growth of Trichophyton rubrum is reported. The effects varied from complete inhibition of growth to stimulation. Highly inhibitory compounds included androstan-3,17dione, testosterone, 11-deoxycorticosterone, progesterone and 7-dehydrocholesterol. 17 1 -Hydroxypregnenolone was stimulatory but all other compounds with the $17 \alpha$-hydroxyl group were inactive. Structural requirements for activity are discussed.
\end{abstract}

\section{INTRODUCTION}

Steroid derivatives have been reported to influence micro-organisms in a variety of ways-being essential growth factors for certain species (e.g. Edward \& Fitzgerald, 1951; Butler \& Knight, 1960; Van Wagtendonk, Conner, Miller \& Rao, 1953); stimulators of growth for others (Buetow \& Levedahl, 1957; Jefferson \& Sisco, 1959); but most frequently growth inhibitors (e.g. Lester, Stone \& Hechter, 1958). Included among the organisms for which inhibitions by steroids have been reported are several dermatophytes (Reiss, 1949; Tarbet, Oura \& Sternberg, 1953; Casas-Campillo, Balandrano \& Galarza, 1960). The dermatophytes are of particular interest since changes in the incidence of fungal infections have been noted at times of variation in the content of steroid hormones in the tissue. Microsporum infections usually cure spontaneously at puberty and dissemination of Trichophyton infections has been noted in association with Cushing's syndrome (Nelson \& McNiece, 1959) and during cortisone therapy (Cremer, 1955). Thus steroids may influence either directly or indirectly the development of these infections and it seemed of interest to study in more detail the nature of the effect of these substances upon the fungi themselves. A preliminary report (Chattaway, Townsley \& Barlow, 1959) showed the effect of a small number of steroids upon several dermatophytes. In the present paper this has been extended to a study of the effect of 37 steroids upon Trichophyton rubrum.

\section{METHODS}

Organism. The strain used was the OS strain of Trichophyton rubrum isolated from a foot infection in 1958.

Medium and inoculum. The growth medium contained (per 9.5 ml.): L-glutamic acid, $21 \mathrm{mg}$.; $\mathrm{KH}_{2} \mathrm{PO}_{4}, 18 \mathrm{mg}$.; $\mathrm{MgSO}_{4} .7 \mathrm{H}_{2} \mathrm{O}, 1 \mathrm{mg}$; D-glucose, $100 \mathrm{mg}$.; D-biotin, 


\section{F. W. Chattaway, J. D. Townsley and A. J. E. Barlow}

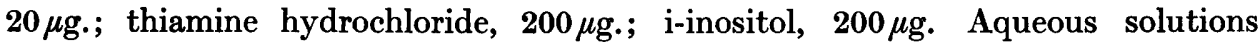
adjusted to $\mathrm{pH} 6.8$ containing glutamic acid, vitamins and phosphate were autoclaved (121 ${ }^{\circ}$ for $10 \mathrm{~min}$.) separately from those containing glucose and magnesium sulphate. Medium (9.5 ml.) was placed aseptically in $100 \mathrm{ml}$. conical flasks and its volume made $10 \mathrm{ml}$. by addition of the inoculum, which consisted of homogenized washed mycelium suspended in sterile water, having been grown initially on Sabouraud's maltose broth.

Steroids were added in chloroform ethanol $(1+1, \mathrm{v} / \mathrm{v})$ solution to the sterile $100 \mathrm{ml}$. conical flasks and the solvent removed by evaporation for $18 \mathrm{hr}$. at $33^{\circ}$ before addition of medium.

Measurement of growth. This was done by determination of mycelial dry weight by filtering on to dried and weighed Whatman No. 1 filter paper $(3.0 \mathrm{~cm}$. diam.), washing three times with $50 \mathrm{ml}$. distilled water and drying at $105^{\circ}$ for $18 \mathrm{hr}$. All such determinations were made in triplicate and after incubation at $33^{\circ}$ for 7 days.

\section{RESULTS}

The earlier survey showed that 11-deoxycorticosterone was highly inhibitory and the effect of different concentrations showed that $50 \%$ inhibition of growth occurred at $17 \mu \mathrm{g} . / \mathrm{ml}$. and maximal inhibition at $75 \mu \mathrm{g} . / \mathrm{ml}$.

For routine testing steroids were examined at $250 \mu \mathrm{g} . / \mathrm{ml}$. medium; the results are shown in Table 1. All compounds were tested on at least three separate occasions. Results are expressed as percentage inhibition or stimulation of growth in the absence of steroid. The normal growth was determined at the same time. Some of the compounds previously tested were included for completeness. While no close correlation of structure with activity can be discerned, some structural requirements can be seen. A considerable number of the compounds with high inhibitory activity are $\mathrm{C}_{17}$ or $\mathrm{C}_{19}$ steroids and all such compounds have a $\mathrm{C}_{3}$ carbonyl group; reduction of this to a $3 \alpha$ - or $3 \beta$-hydroxyl group leads to considerable decrease or complete loss of inhibitory effect. Among inhibitory compounds the $\mathrm{C}_{3}$ carbonyl group is often accompanied by unsaturation between $\mathrm{C}_{4}$ and $\mathrm{C}_{5}$, but this is not essential for activity since androstan-3,17-dione and $5 \beta$-androsten-3-one-17 $\beta$-ol displayed high activity. The activity of the latter compound also suggests that the planarity of the steroid nucleus is not an essential feature. The nature of substituents at $\mathrm{C}_{17}$ afford some interesting comparisons. Thus high activity is seen with a $\mathrm{C}_{17}$ carbonyl, $\beta$-hydroxyl, $\beta$-acetyl and $\beta$-acetoxy groups and with an 8 -carbon side-chain, but the presence of a $17 \alpha$-hydroxyl group leads to complete loss of activity. Substitution at other sites (e.g. $\mathrm{C}_{9}$ or $\mathrm{C}_{11}$ ) also leads to reduction or loss of activity.

The series of sterols is of some interest since activity is seen with 7-dehydrocholesterol, lumisterol and ergosterol all of which have a $\Delta^{5,7}$-diene structure while the six compounds with the $3 \beta$-hydroxyl and $\Delta^{5}$ double bond all show no inhibition or slight stimulation. Combination of this structure with a 17-hydroxyl group as in $17 \alpha$-hydroxypregnenolone causes appreciable stimulation of growth.

There appears to be no parallel between inhibitory power and known function in mammals; thus 11-deoxycorticosterone displays high activity while $2 \alpha$-methyl$9 \alpha$-fluoro-hydrocortisone, the most active mineralocorticoid known, was without inhibitory effect. Similarly corticosterone displayed some activity while the much 
more powerful glucocorticoid $16 \alpha$-methyl-9 $\alpha$-fluoro-prednisolone was without activity. Also compounds such as androstan-3,17-dione showed high activity while possessing no great hormonal activity in the mammal.

Table 1. Effect of steroids on growth of Trichophyton rubrum, strain OS

Results are expressed as \% inhibition (+ve) or stimulation ( - ve) of growth in the presence of $250 \mu \mathrm{g}$. steroid $/ \mathrm{ml}$. medium as compared with growth obtained in the absence of added steroid. The steroids are listed in order of decreasing inhibitory effects.

$\begin{array}{llc}\text { Compound } & \begin{array}{c}\text { Mean \% } \\ \text { expts. }\end{array} & \begin{array}{c}\text { inhibition or } \\ \text { stimulation }\end{array}\end{array}$

\begin{tabular}{|c|c|c|}
\hline Androstan-3,17-dione & 4 & 96 \\
\hline$\Delta^{1}$-androsten-3,17-dione & 4 & 96 \\
\hline Nortestosterone & $\mathbf{3}$ & 94 \\
\hline 11-deoxycorticosterone* & 4 & 91 \\
\hline$\Delta^{4}$-androsten-3,17-dione & 4 & 89 \\
\hline $5 \beta$-androstan-3-one-17 $\beta$-ol & $\mathbf{3}$ & 88 \\
\hline Calciferol* & 4 & 79 \\
\hline Testosterone* & 4 & 77 \\
\hline 7-Dehydrocholesterol* & 4 & 77 \\
\hline$\Delta^{1,4}$-androstadiene-3-one-17 $\beta$-ol & $\mathbf{3}$ & 7 \\
\hline Progesterone* & 4 & 70 \\
\hline $5 \alpha$-androstan-3-one-17 $\beta$-ol & $\mathbf{3}$ & 62 \\
\hline $11 \alpha$-hydroxyprogesterone* & 4 & $\mathbf{5 9}$ \\
\hline Androsterone & $\mathbf{3}$ & 57 \\
\hline Corticosterone & 4 & 44 \\
\hline Lumisterol & 4 & 42 \\
\hline Oestradiol-17 $\beta^{*}$ & 4 & 39 \\
\hline Oestradiol-17 $\alpha^{*}$ & 4 & 39 \\
\hline Ergosterol & $\mathbf{3}$ & 28 \\
\hline Epitestosterone & $\mathbf{3}$ & 20 \\
\hline Oestrone & 3 & 11 \\
\hline$\Delta^{5}$-androsten-3 $\beta, 17 \beta$-diol & $\mathbf{3}$ & 10 \\
\hline $17 \alpha$-hydroxyprogesterone & $\mathbf{3}$ & 10 \\
\hline Prednisolone & $\mathbf{3}$ & \\
\hline Androstan- $3 \alpha, 17 \beta$-diol & $\mathbf{3}$ & \\
\hline Aldosterone & $\mathbf{1}$ & \\
\hline Pregnenolone & 3 & \\
\hline Hydrocortisone* & 4 & - \\
\hline Cortisone* & 4 & -3 \\
\hline $17 \alpha$-hydroxy-11-deoxycorticosterone & 4 & -4 \\
\hline Lanosterol* & 4 & $-\mathbf{5}$ \\
\hline $2 \alpha$-methyl-9 $\alpha$-fluorohydrocortisone & $\mathbf{3}$ & $-\mathbf{9}$ \\
\hline $9 \alpha$-fluorohydrocortisone & 3 & -12 \\
\hline Stigmasterol & 3 & -14 \\
\hline Cholesterol* & 4 & -18 \\
\hline Sitosterol & $\mathbf{3}$ & -18 \\
\hline $17 \alpha$-hydroxypregnenolone & $\mathbf{3}$ & -37 \\
\hline
\end{tabular}

\section{DISCUSSION}

There has been some emphasis in the literature on the marked ability of 11-deoxycorticosterone to inhibit fungal growth; thus Lester et al. (1958) reported it as the most active steroid in a group of 33 which inhibited the growth of Neurospora crassa, 


\section{F. W. Chattaway, J. D. Townsley and A. J. E. Barlow}

Tarbet et al. (1953) found a similar result with Microsporum gypseum and CasasCampillo et al. (1960) reported that it, together with 19-norprogesterone, was the most effective inhibitor of Trichophyton mentagrophytes. The present study also shows this compound to have high activity against $T$. rubrum, but nor-testosterone and androstane-3,17-dione were equally potent inhibitors and compounds with such widely different biological activity as calciferol and progesterone showed activity little below that of 11-deoxycorticosterone. Thus little support is given by the present work to the concept that steroids in micro-organisms may control processes analogous to those under hormonal control in mammals. Evidence in support of this concept was advanced by Lester \& Hechter (1959) in the effect of 1-deoxycorticosterone on sodium and potassium concentration in $N$. crassa and by the same authors (1961) in the antagonistic effects displayed by oestradiol-17 $\beta$ and 11-deoxycorticosterone upon the growth of Penicillium puberulum. The inhibitory activity of testosterone on $T$. rubrum is comparable with that reported by Reiss (1949) for dermatophytes, Lester et al. (1958) for $N$. crassa and Maxwell, McGuire \& Tomkins (1960) for Saccharomyces fragilis. Tarbet et al. (1953), however, found it to be slightly stimulatory for $\boldsymbol{M}$. gypseum when assayed by its effect on the germination of macroconidia. Similarly androstan-3,17-dione and $\Delta^{1}$-androsten-3,17-dione were reported to have fungistatic effects (Maxwell et al. 1960) and the inactivity of $17 x$-hydroxy steroids has been reported by a number of workers. Thus in general it appears that growth of $T$. rubrum was optimally inhibited by $\mathrm{C}_{17}$ or $\mathrm{C}_{19}$ steroids with a $\mathrm{C}_{3}$-carbonyl substituent associated with a variety of $\mathrm{C}_{17}$ substituents of the $\beta$-configuration and that such activity was decreased by modifications at other sites in the molecule and abolished by the presence of a $17 \alpha$-hydroxyl group.

Of the sterols tested ergosterol has been reported as inhibitory for Penicillium chrysogenum; stimulatory for the growth of other moulds (Matkovics, 1957, Matkovics \& Sipos, 1959) and without effect upon Neurospora crassa (Lester et al. 1958). The low inhibitory activity of ergosterol for Trichophyton rubrum is of interest since this compound has been found in the normal mycelium (unpublished results). The considerable inhibitory power of 7-dehydrocholesterol, calciferol and lumisterol does not appear to have been recorded previously. The low stimulatory power of cholesterol, stigmasterol and sitosterol together with the marked stimulation by $17 \alpha$-hydroxypregnenolone suggests that structures may be found which have even greater powers of stimulation.

We wish to thank the Wellcome Trust for a grant towards the expenses involved in this work and for a maintenance grant to one of us (J.D.T.). Gifts of steroids kindly given by Organon Ltd., Upjohn Co., E. R. Squibb and Sons, Glaxo Laboratories and Professor B. Lythgoe are gratefully acknowledged. We are also indebted to Dr Jacqueline Walker for the organism used in this work and to Professor B. Lythgoe for helpful discussions. 


\section{REFERENCES}

Buetow, D. E. \& Levedahl, B. H. (1957). The effects of steroids on the growth of Euglena gracilis. Arch. Biochem. Biophys. 73, 273.

Butler, M. \& KNight, B. C. J. G. (1960). Steroid growth requirements and steroid growth inhibitors of Mycoplasma. J. gen. Microbiol. 22, 483.

Casas-Campillo, C., Balandrano, D. \& Galarza, A. (1960). Steroids CliX. Antimicrobial properties of 21,21-dimethoxyprogesterone analogues. J. Bact. 81, 366.

Chattaway, F. W., Townsley, J. D. \& Barlow, A. J. E. (1959). Effect of steroids and related compounds on the growth of dermatophytes. Nature, Lond. 184, 1731.

Cremer, G. (1955). Influence of adrenocortical hormones on dermatomycoses. Especially in Cushing's syndrome. Dermatologica, 111, 285.

Edward, D. G. ff. \& Fitzerald, W. A. (1951). Cholesterol in the growth of organisms of the pleuropneumonia group. J.gen. Microbiol. 5, 576.

Jefrerson, W. E. \& Sisco, G. (1959). The response of Aspergillus niger to added steroids. Fed. Proc. 18, 253.

Lester, G. \& Hechter, O. (1959). The relationship of sodium, potassium and deoxycorticosterone in Neurospora crassa. Proc. nat. Acad. Sci., Wash. 45, 1792.

Lester, G. \& Hechter, O. (1961). Growth regulation in Penicillium puberulum by oestradiol-17 $\beta$ and deoxycorticosterone. J. Bact. 81, 803.

Lester, G., Stone, D. \& Hechter, O. (1958). The effects of deoxycorticosterone and other steroids on Neurospora crassa. Arch. Biochem. Biophys. 75, 196.

Matкovics, B. (1957). Über die Wirkung von Sterinen auf Microorganismen. Naturwissenschaften, 44, 400 .

Matkovics, B. \& Sipos, G. (1959). Effects of sterols on the growth of microorganisms. Acta Univ. Szeged. 5, 25.

Matkovics, B. (1960). Action of sterols on growth of microorganisms. Pharmazie, 15, 122.

Maxweld, E. S., McGuire, J. S. \& Tomkins, G. N. (1960). Antibiotic effect of steroids on Saccharomyces fragilis and the isolation of a resistant mutant. J. Bact. 80, 1.

Nelson, L. M. \& MCNiecE, K. J. (1959). Recurrent Cushing's syndrome with Trichophyton rubrum infection. Arch. Derm. 80, 700.

Reiss, F. (1949). Steroid hormones; their fungistatic and genestatic effect on pathogenic fungi. Arch. Derm. Syph. (Berl.) 59, 405.

Tarbet, J. E., Oura, M. \& Sternberg, T. H. (1953). Microassay of antifungal properties of steroid hormones and other compounds. Mycologia, 45, 627.

van Wagendonk, W. J., Conner, R. L., Miller, C. A. \& Rao, M. R. R. (1953). Growth requirements of Paramecium aurelia var. 4 : stock 51.7 sensitives and killers in axenic medium. Ann N.Y. Acad. Sci. 56, 929. 